\title{
The haemodynamic response to exercise in chronic obstructive pulmonary disease: assessment by impedance cardiography
}

\author{
H.J. Bogaard, B.M. Dekker, B.W.G.J. Arntzen, H.H. Woltjer, A.R.J. van Keimpema, \\ P.E. Postmus, P.M.J.M. de Vries
}

The haemodynamic response to exercise in chronic obstructive pulmonary disease: assessment by impedance cardiography. H.J. Bogaard, B.M. Dekker, B.W.G.J. Arntzen, H.H. Woltjer, A.R.J. van Keimpema, P.E. Postmus, P.M.J.M. de Vries. CERS Journals Ltd 1998. ABSTRACT: This study aimed to determine the differences in haemodynamic responses to a standard incremental exercise test between outpatients with chronic obstructive pulmonary disease (COPD) and age-matched controls and to discover the relationship between severity of airflow obstruction and exercise haemodynamics in COPD.

Twenty-two male patients with COPD (forced expiratory volume in one second $(\mathrm{FEV} 1) /$ vital capacity $(\mathrm{VC}))<80 \%$ predicted) and 20 age-matched male controls performed an incremental exercise test $\left(10 \mathrm{~W} \cdot \mathrm{min}^{-1}\right)$ with ventilatory function and changes in stroke volume $(\Delta \mathrm{SV})$ and cardiac output $(\Delta \mathrm{CO})$ measured by means of electrical impedance cardiography (EIC).

Submaximal $\Delta \mathrm{SV}$ and $\Delta \mathrm{CO}$ were lower in COPD patients. Peak exercise $\Delta \mathrm{SV}$ were equal in patients and controls $(128 \pm 33$ versus $129 \pm 29 \%, \mathrm{p}=0.98)$, whereas peak $\Delta \mathrm{CO}$ was lower in patients (COPD versus controls: $232 \pm 71$ versus $289 \pm 54 \%, p<0.005$ ). In COPD patients, FEV1 (\% pred) was significantly correlated to $\Delta \mathrm{SV}$ at all submaximal exercise intensities, to peak exercise $\Delta \mathrm{SV}$ and to peak exercise $\Delta \mathrm{CO}$. FEV1/VC (\% pred) was significantly correlated to $\Delta \mathrm{SV}$ at 30 and $60 \mathrm{~W}$.

In conclusion, in chronic obstructive pulmonary disease an aberrant haemodynamic response to exercise was found, especially in patients with severe airflow obstruction. This aberrant response is related to the degree of airflow obstruction and may limit exercise performance in patients with severe chronic obstructive pulmonary disease. Eur Respir J 1998; 12: 374-379.

In most patients with chronic obstructive pulmonary disease (COPD) maximal exercise capacity is diminished, but pulmonary function tests provide a poor prediction of peak exercise oxygen consumption $\left(V^{\prime} \mathrm{O}_{2}\right)$ [1-3]. An aberrant haemodynamic response may contribute to the decreased exercise tolerance $[4,5]$. Therefore, direct assessment of cardiac function would provide valuable additional information for the evaluation of individual patients. Lack of availability of noninvasive methods has prohibited the incorporation of haemodynamic measurements during a standard exercise test. Electrical impedance cardiography (EIC), the validity of which has been shown recently in patients with airflow obstruction [6-8], might be an appropriate alternative.

The aim of this study was to determine the value of haemodynamic measurements during standard exercise testing in COPD. First, in a select group of outpatients with known COPD it was assessed whether an aberrant haemodynamic response was found. A comparison was made between the haemodynamic response of 20 healthy subjects and 22 patients. Secondly, the relationship was investigated between disease severity (reflected by pulmonary function) and exercise haemodynamics. Thirdly, the relationship between peak exercise performance and the EIC-derived haemodynamic response to exercise was investigated.
Dept of Pulmonary Medicine, Academic Hospital VU, Amsterdam, The Netherlands.

Correspondence: H.J. Bogaard

Academic Hospital VU

Dept of Pulmonary Medicine

P.O. Box 7057

1007 MB Amsterdam

The Netherlands

Fax: 31204444328

Keywords: Chronic obstructive pulmonary disease

exercise

haemodynamics

impedance cardiography

stroke volume

Received: August 271997

Accepted after revision March 31998
Subjects and methods

\section{Study subjects}

Twenty-two male COPD patients and 20 age-matched male healthy control subjects participated in this study. Anthropometric and pulmonary function data are summarized in table 1. Selection of patients was based on the following criteria: 1) clinical diagnosis of COPD; 2) forced expiratory volume in one second $(\mathrm{FEV} 1)<80 \%$ predicted (reference values from [9]); and 3) oxyhaemoglobin saturation $\left(\mathrm{S}_{\mathrm{a}} \mathrm{O}_{2}\right.$, measured with a pulse oximeter) $\breve{\mathrm{S}} 90 \%$ at rest. All patients were outpatients, who were stable at the time of investigation and used inhaled bronchodilators and corticosteroids. All control subjects had a normal pulmonary function. Additional inclusion criteria for both groups were: 1) no clinical evidence of cardiovascular disease; 2) no cardiovascular medication; 3) no pathology possibly interfering with the ability to perform exercise (e.g. diseases of the locomotor or central nervous system and malignancy); 4) normal resting electrocardiogram (ECG); and 5) no regular participation in endurance exercise training, defined as more than 30 min of such activity more than three times a week. The investigation was approved by the Ethical Committee of the Academic Hospital VU, Amsterdam, and informed consent was obtained from all participants. 
Table 1. - Characteristics and lung function variables of 20 control subjects and 22 patients with chronic obstructive pulmonary disease (COPD)

\begin{tabular}{lcccc}
\hline & Controls & Subjects & COPD & $\%$ pred \\
\hline Subjects & 20 & & 22 & \\
Age yrs & $53.4 \pm 4.14$ & & $51.3 \pm 13.8$ & \\
Weight kg & $79.3 \pm 13.0$ & & $78.8 \pm 11.7$ & \\
Height m & $1.75 \pm 0.07$ & & $1.76 \pm 0.10$ & \\
VC L & $5.21 \pm 0.70$ & $123 \pm 18$ & $4.08 \pm 0.83^{+}$ & $94 \pm 17^{+}$ \\
FEV1 L & $3.82 \pm 0.42$ & $110 \pm 13$ & $2.07 \pm 0.83^{+}$ & $56 \pm 17^{+}$ \\
FEV1/VC \% & $74 \pm 9$ & $95 \pm 12$ & $50 \pm 16^{+}$ & $64 \pm 21^{+}$ \\
$W_{\max }$ W & $217 \pm 40$ & & $144 \pm 47^{+}$ & \\
$V^{\prime} \mathrm{O}_{2}$ max & & & & \\
$\mathrm{L}^{\prime} \mathrm{min}^{-1} \cdot \mathrm{m}^{-2}$ & $1.39 \pm 0.27$ & & $0.94 \pm 0.27^{+}$ & \\
\hline
\end{tabular}

Values are shown as mean \pm sD. VC: vital capacity; FEV1: forced expiratory volume in one second; $W$ max: workload at peak exercise intensity; $V^{\prime} \mathrm{O}_{2}$ max: oxygen consumption at peak exercise intensity; \% pred: predicted values, derived from QUANER $e t$ al. [9]. ${ }^{*} \mathrm{p}<0.0001$, significant difference from controls.

\section{Study design}

After evaluation of pulmonary function, all subjects performed a symptom-limited exercise test during which standard gas-exchange measurements were combined with haemodynamic measurements by means of EIC.

\section{Methods}

Pulmonary function was evaluated by an assessment of static and dynamic lung volumes (Masterlab; Jaeger, Würzburg, Germany) and measured values were compared to the predicted values derived from [9]. Stroke volume measurement was performed by means of EIC (IPG-104 impedance Mini-lab; RJL Systems, Detroit, MI, USA, and Sanofi Santé, Maassluis, The Netherlands). This technique relates changes in thoracic impedance to changes in thoracic blood volume. A constant sinusoidal alternating current of $0.8 \mathrm{~mA}$ and $60 \mathrm{kHz}$ is introduced through one spot electrode (Red Dot; 3M, St Paul, MN, USA) on the

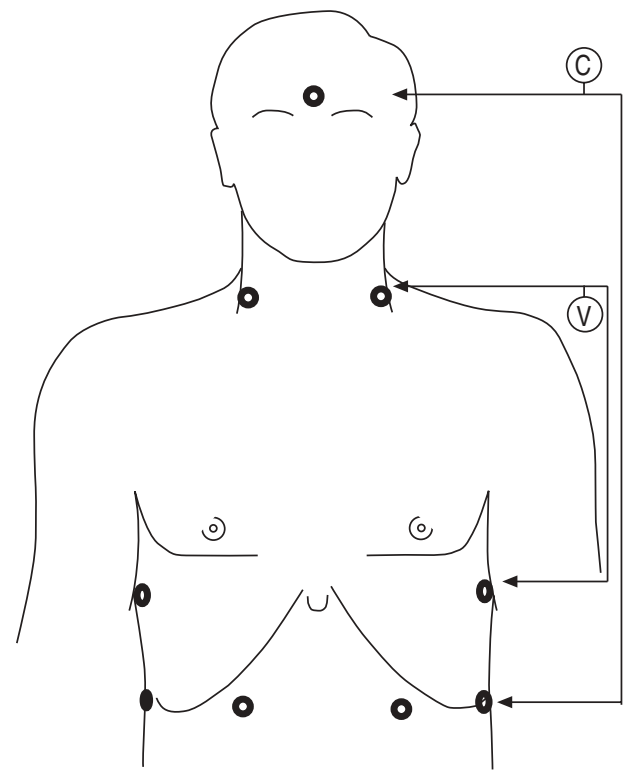

Fig. 1. - Electrode array. C: introduction of current; V: measurement of voltage. Electrodes at a given body level are connected in parallel. Impedance is calculated according to Ohm's law. forehead and four electrically connected electrodes at the lower abdomen (fig. 1). Changes in voltage are detected between one pair of electrodes in the midaxillary lines at the base of the neck and another at a fixed distance ( $L=$ $0.17 \times$ height) below. This electrode configuration has been developed and validated in the authors' own laboratory. It is a modification of the Kubicek electrode configuration [10], is easier to apply and gives comparable results [11].

The signal that is thus acquired is depicted in figure 2 . The A-wave of the $\mathrm{d} Z / \mathrm{d} t$ recording follows the P-wave of the ECG and corresponds to atrial systole. The B-point represents the opening of the aortic valves. The $\mathrm{C}$-wave appears after the QRS-complex and reflects the rate of blood flow ejection from the left ventricle. The C-wave terminates at the $\mathrm{X}$-point, the closure of the aortic valves. The time between $\mathrm{B}$ and $\mathrm{X}$ is the left ventricular ejection time (LVET).The O-wave occurs after the T-wave of the ECG and corresponds to rapid ventricular filling during diastole. Stroke volume (SV) is calculated according to the formula of KUBiCEK [10]:

$$
\mathrm{SV}=\rho \times\left(L / Z_{0}\right)^{2} \times \mathrm{d} Z / \mathrm{d} t \max \times \mathrm{LVET}
$$

where $\rho=$ resistivity of blood (calculated as $53.2 \mathrm{e}^{0.022 \times \text { haemat- }}$ ocrit [12]), $\mathrm{Z}_{\mathrm{o}}=$ baseline thoracic impedance and $\mathrm{d} Z / \mathrm{d} t \max =$ the maximum change in impedance during systole. Measurements are made continuously and processed by a computer. SV is calculated with a computer-derived averaged signal of 20 consecutive heart beats. Cardiac output (CO) is calculated as $\mathrm{SV} \times$ cardiac frequency $(f \mathrm{C})$.

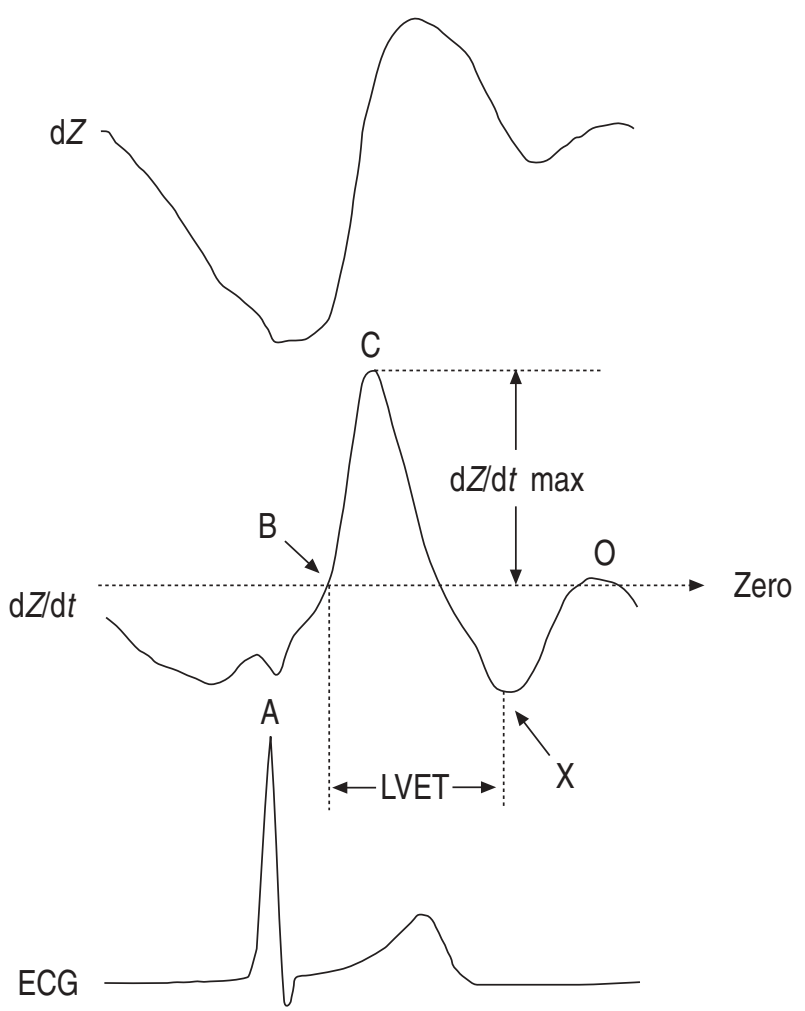

Fig. 2. - Ideal $\mathrm{d} Z, \mathrm{~d} Z / \mathrm{d} t$ and electrocardiographic (ECG) signal. The impedance cardiogram is traditionally recorded with negative values upward. A: atrial contraction wave; B: start of left ventricular ejection; $\mathrm{C}$ : major systolic deflection; X: aortic valvular closure; $\mathrm{O}$ : diastolic deflection; LVET: left ventricular ejection time. 
The validity of SV measurements by means of EIC has been extensively shown in healthy subjects and cardiac patients $[13,14]$. Comparisons have been made with a wide range of invasive techniques, e.g. the direct Fick method $[15,16]$, dye-dilution $[17,18]$ and with the technique of $\mathrm{CO}_{2}$ rebreathing $[19,20]$. Correlation coefficients between SV measurement using EIC and the reference method ranged 0.87-0.94. During strenuous exercise, however, motion and respiratory artefacts can become a large technological impediment. With recently developed computer averaging techniques random artefacts are removed and the signal-to-noise ratio is increased [21-23]. Further improvement is obtained by replacing band electrodes by spot electrodes [11, 23].

As a result of the invasive nature of reference methods, validation during exercise has been restricted to patients for whom invasive diagnostic methods were already indicated because of suspected cardiac disease. Recently, PIANosI [6] showed accurate EIC measurements of $\mathrm{CO}$ in a group of children with cystic fibrosis. Using the method described in this paper, we reported in exercising COPD patients a mean difference between EIC and the reference method of $0.5 \mathrm{~mL}$ with a limit of agreement $(2 \mathrm{sD})$ of 20 $\mathrm{mL}$ for measurements during exercise [7] and an intraobserver and interobserver variability of $<5 \%$ [8]. Nevertheless, as the validation of EIC in COPD is limited, our analyses in this study were based on changes in $\mathrm{SV}(\Delta \mathrm{SV})$ and $\mathrm{CO}(\Delta \mathrm{CO})$, (both expressed as percentages of the resting value) rather than on absolute values. In COPD, cardiac reserve is reduced, whereas resting cardiac performance is normal [5]. Therefore, differences in $\Delta \mathrm{SV}$ and $\Delta \mathrm{CO}$ between normal subjects and COPD patients are equally important as differences in absolute values.

The exercise test was performed on a bicycle ergometer (Ergoline 900; Blitz, Germany) in the upright position. The exercise protocol consisted of 3 min of unloaded pedalling followed by a stepwise load increase of $10 \mathrm{~W} \cdot \mathrm{min}^{-1}$, until maximal tolerable load was reached (symptom limited). Measurements of $V^{\prime} \mathrm{O}_{2}$, carbon dioxide output $\left(V^{\prime} \mathrm{CO}_{2}\right)$, minute ventilation $\left(V^{\prime} \mathrm{E}\right)$ and tidal volume $(V \mathrm{~T})$ were made breath-by-breath using an open system (Oxycon Gamma; Mijnhardt, Bunnik, The Netherlands). Calculations were made of ventilatory equivalents for oxygen $\left(E q \mathrm{O}_{2}=V^{\prime} \mathrm{E} /\right.$ $\left.V^{\prime} \mathrm{O}_{2}\right)$, ventilatory equivalents for carbon dioxide $\left(E q \mathrm{CO}_{2}=\right.$ $\left.V^{\prime} \mathrm{E} / V^{\prime} \mathrm{CO}_{2}\right)$ and oxygen pulse $\left(\mathrm{O}_{2}\right.$ pulse $\left.=V^{\prime} \mathrm{O}_{2} / f \mathrm{C}\right)$. Haemoglobin oxygen saturation was recorded continuously by pulse-oximetry (Datascope; Datex, Helsinki, Finland). Electrocardiographic measurements (Hellige, Freiburg, Germany) were performed continuously and blood pressure was determined by sphygmomanometry every $3 \mathrm{~min}$.

\section{Statistical analyses}

Analysis of the patterns of change in the haemodynamic variables during exercise. Repeated measurements analysis of variance (ANOVA) was used to detect an overall exercise effect in $f \mathrm{C}, \Delta \mathrm{SV}$ and $\Delta \mathrm{CO}$. Post hoc testing comprised unpaired Student's t-tests. Differences in resting and peak exercise values between the two groups were also analysed by unpaired Student's t-tests. In the case of nonparametric distributions of variables, the Friedman test was used instead of repeated measurements ANOVA, the Wilcoxon signed-rank test instead of the paired Student's t-test and the Mann-Whitney test instead of the unpaired Student's t-test. Whenever multiple comparisons were made, a Bonferroni correction was applied to the significance level.

Analysis of the influence of disease severity (reflected by pulmonary function) on the haemodynamic response. Pearson's correlation coefficients were calculated between FEV1 (\% pred) and FEV1/VC (\% pred) on the one hand, and $\triangle \mathrm{SV}$ and $\triangle \mathrm{CO}$ at different exercise intensities on the other hand.

Assessment of the relationship of the haemodynamic variables $\triangle S V$ and $\triangle C O$ to peak exercise performance. Pearson's correlation coefficients were calculated between peak $V^{\prime} \mathrm{O}_{2}$ and $\Delta \mathrm{SV}$ and $\Delta \mathrm{CO}$ at different exercise intensities.

\section{Results}

The two groups were comparable with respect to age, height and weight, while significant differences were found in pulmonary function, peak exercise intensity $\left(W_{\max }\right)$ and peak $V^{\prime} \mathrm{O}_{2}$ (table 1). Of all subjects studied, only two COPD patients had $\mathrm{Sa}_{\mathrm{a}} \mathrm{O}_{2}<90 \%$ towards the end of exercise. Differences in group means were not significant.

\section{Haemodynamic responses}

$f C$ was higher in COPD patients than in controls at 90 $\mathrm{W}$ and at peak exercise (fig. 3 ). $\Delta \mathrm{SV}$ was significantly less in patients than in controls at 30,60 and $90 \mathrm{~W}$. At maximum exercise, $\Delta \mathrm{SV}$ decreased compared to submaximal exercise in controls, whereas in patients $\Delta \mathrm{SV}$ remained constant. Therefore, no differences in $\triangle \mathrm{SV}$ were found between the two groups at this level (COPD versus controls: $128 \pm 33$ versus $129 \pm 29 \%$, fig. 4 ). At all submaximal, as well as at peak exercise intensity, $\Delta \mathrm{CO}$ was higher in controls than in COPD patients (peak exercise, COPD versus controls: $232 \pm 71$ versus $289 \pm 54 \%, \mathrm{p}<0.005$, fig. $5)$. No differences were found in blood pressure responses.

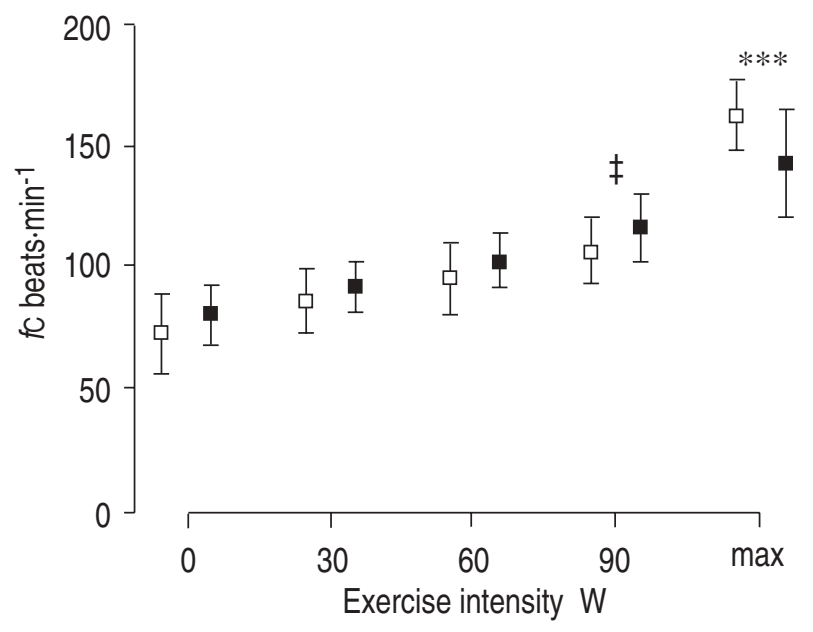

Fig. 3. - Cardiac frequency $(f \mathrm{c})$ during exercise in 22 patients with chronic obstructive pulmonary disease (ם) and 20 control subjects (घ). $\mathrm{p}<0.02$; ***: $\mathrm{p}<0.001$. 


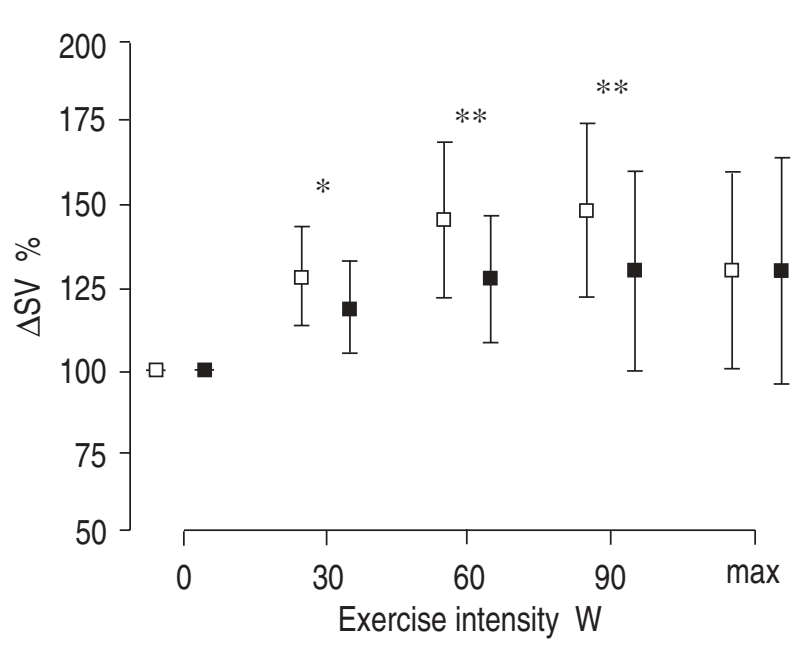

Fig. 4. - Change in stroke volume $(\Delta \mathrm{SV})$ during exercise in 22 patients with chronic obstructive pulmonary disease (ם) and 20 control subjects (घ). *: $\mathrm{p}<0.05 ; * *: \mathrm{p}<0.01$.

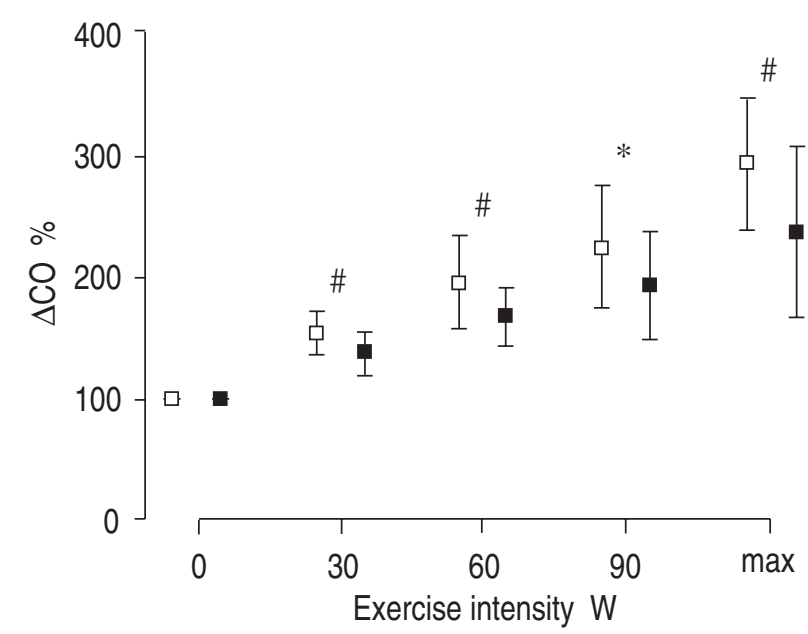

Fig. 5. - Change in cardiac output $(\Delta \mathrm{CO})$ during exercise in 22 patients with chronic obstructive pulmonary disease (ם) and 20 control subjects (घ). \#: $\mathrm{p}<0.005 ; *: \mathrm{p}<0.05$.

Table 2. - Significant correlations between disease severity and the change in stroke volume ( $\Delta S \mathrm{SV})$ and cardiac output $(\triangle \mathrm{CO})$ during exercise in 22 patients with chronic obstructive pulmonary disease (COPD)

\begin{tabular}{cccc}
\hline & & FEV1 \% pred & $\mathrm{FEV}_{1} / \mathrm{VC} \%$ pred \\
\hline$\Delta \mathrm{SV} \%$ & $30 \mathrm{~W}$ & $0.54^{* *}$ & $0.48^{*}$ \\
& $60 \mathrm{~W}$ & $0.54^{* *}$ & $0.48^{*}$ \\
& $90 \mathrm{~W}$ & $0.45^{*}$ & - \\
\multirow{4}{*}{$\mathrm{CO} \%$} & $W \max$ & $0.43^{*}$ & - \\
& $30 \mathrm{~W}$ & - & - \\
& $60 \mathrm{~W}$ & - & - \\
& $90 \mathrm{~W}$ & - & - \\
& $W \max$ & $0.47^{*}$ & - \\
\hline
\end{tabular}

Disease severity is reflected by the forced expiratory volume in one second (FEV1) and FEV1/vital capacity (VC), both expressed as percentages of predicted [9]. $W_{\text {max }}$ : workload at peak exercise intensity. $*$ : $\mathrm{p}<0.05 ; * *: \mathrm{p}<0.01$.

Influence of disease severity on the haemodynamic response to exercise

In table 2 Pearson's correlation coefficients are shown between disease severity (reflected by FEV1 and FEV1/
$\mathrm{VC}$, both expressed as percentages of predicted), and $\Delta \mathrm{SV}$ and $\triangle \mathrm{CO}$ at the different exercise intensities. In control subjects, such correlations were not found. No significant correlations were found, either in controls or in COPD patients between disease severity and $E q \mathrm{O}_{2}, E q \mathrm{CO}_{2}$ or $\mathrm{O}_{2}$ pulse during exercise.

\section{Relationship between haemodynamics and peak $\mathrm{VO}_{2}$}

$\Delta \mathrm{SV}$ was not correlated to peak $V^{\prime} \mathrm{O}_{2}$ at any exercise intensity. Peak exercise $\triangle \mathrm{CO}$ was significantly correlated to peak $V^{\prime} \mathrm{O}_{2}(\mathrm{r}=0.66, \mathrm{p}<0.001)$. No correlations between submaximal exercise $\Delta \mathrm{CO}$ and peak $V^{\prime} \mathrm{O}_{2}$ were found.

\section{Discussion}

A clear difference was found in the haemodynamic response to exercise between patients and controls. The increase in SV in COPD during exercise was diminished, which was insufficiently compensated for by an augmentation in $f \mathrm{C}$. Therefore, the increase in $\mathrm{CO}$ was reduced in patients. At peak exercise, no differences in $\Delta \mathrm{SV}$ were found. This was due to a decrease in SV towards the end of exercise in controls, which is a normal exercise response in healthy elderly subjects $[24,25]$. With the onset of exercise, venous return is increased, as well as left ventricular end-diastolic volume (EDV). SV only rises in the initial phase of exercise until $V^{\prime} \mathrm{O}_{2}$ is approximately 40 $60 \%$ of peak $V^{\prime} \mathrm{O}_{2}$. Because of the increase in $f \mathrm{C}$, the rise in EDV is limited or EDV may even decrease. When SV has to be maintained or increased, end-systolic volume (ESV) has to be diminished [26]. The magnitude to which these changes in EDV and ESV can take place depends on total blood volume, heart size and muscle mass, contractility and neuroendocrine function [27]. These factors can all be influenced by deconditioning and training [28, 29], ageing processes [30] and cardiovascular disease. In the COPD patients in this study, left ventricular filling probably did not become critical towards the end of exercise, simply because the test was terminated by dyspnoea, in advance of significant demands on haemodynamic function.

In the group of COPD patients in this study, the degree of airflow limitation was significantly correlated to submaximal $\Delta \mathrm{SV}$ and peak exercise $\Delta \mathrm{CO}$. This suggests that with advancing airflow limitation, cardiocirculatory performance is reduced. Several pathological mechanisms are responsible. During exercise in patients with moderate-to-severe COPD, loss of vascular surface area and alveolar hypoxia (which induces vasoconstriction) may both result in an elevation of mean pulmonary artery pressure [4], thereby increasing right ventricular afterload [3133]. Large intrathoracic pressure swings augment right ventricular afterload even further [34, 35]. The increased right ventricular afterload may lead to right ventricular distension, which in turn distorts the geometry of the interventricular septum. Thus, left ventricular pumping activity may also be impeded [36]. In addition, the inspiratory drop in pleural pressure, which is larger in COPD, increases left ventricular transmural pressure [37]. Finally, in most patients with mild airflow obstruction, deconditioning, 
which has mainly cardiovascular effects, is an important factor limiting exercise [38-40].

In the present study, patients with clinical or ECG evidence of cardiovascular disease were excluded. In daily practice, coexisting cardiac and pulmonary pathology will frequently be encountered, and it may be difficult to point out the most important factor in exercise limitation without direct information about cardiac function. Several authors have reported concurrent coronary artery disease in COPD patients [41, 42]. Moreover, in the situation of increased right ventricular wall stress as a result of pulmonary hypertension, myocardial perfusion will be reduced while oxygen need is augmented [43].

In normal subjects, exercise is considered to be limited mainly by the central circulation [27]. In COPD, ventilatory factors are considered critical in exercise performance. Accordingly, no correlations were found between submaximal $\Delta \mathrm{SV}$ and $\Delta \mathrm{CO}$. The positive correlation between peak exercise $\Delta \mathrm{CO}$ and peak $V^{\prime} \mathrm{O}_{2}$ was probably due to the fact that a better ventilatory response allows a higher peak $f C$ and hence a higher peak $\Delta C O$. Interestingly, after subgroup analysis of those COPD patients with a $\mathrm{FEV} 1 / \mathrm{VC}<55 \%$ of predicted, a positive correlation was found between submaximal $\Delta \mathrm{SV}$ and peak $V^{\prime} \mathrm{O}_{2}(\mathrm{r}=0.64$, $\mathrm{p}<0.01$ at $60 \mathrm{~W})$. Therefore, in some patients with severe COPD, exercise performance may be limited by cardiocirculatory factors.

In conclusion, in chronic obstructive pulmonary disease, an aberrant haemodynamic performance can be assessed by means of electrical impedance cardiography. This aberrant response is related to disease severity and may limit exercise performance in severe airflow obstruction.

\section{References}

1. Lewis MI, Belman MJ, Monn SA, Elashoff JD, Koerner SK. The relationship between oxygen consumption and work rate in patients with airflow obstruction. Chest 1994; 106: 366-372.

2. Ortega F, Montemayor T, Sanches A, Cabello F, Castillo J. Role of cardiopulmonary exercise testing and the criteria used to determine disability in patients with severe chronic obstructive pulmonary disease. Am J Respir Crit Care Med 1994; 150: 747-751.

3. LoRusso TJ, Belman MJ, Elashoff JD, Koerner SK. Prediction of maximal exercise capacity in obstructive and restrictive pulmonary disease. Chest 1993; 104: 17481754.

4. Rogers TK, Howard P. Pulmonary hemodynamics and physical training in patients with chronic obstructive pulmonary disease. Chest 1992; 101: Suppl., 289S-292S.

5. Gallagher CG. Exercise limitation and clinical exercise testing in chronic obstructive pulmonary disease. Clin Chest Med 1994; 15: 305-326.

6. Pianosi PT. Impedance cardiography accurately measures cardiac output during exercise in children with cystic fibrosis. Chest 1997; 111: 333-337.

7. Woltjer HH, Bogaard HJ, Vries PMJM. The intra- and interobserver variability of impedance cardiography in patients at rest and during exercise. Physiol Meas 1996; 17: 171-178.

8. Bogaard HJ, Hamersma WBGJ, Horsch JLMI, Woltjer HH, Postmus PE, de Vries PMJM. Noninvasive assessment of cardiac output during exercise in COPD: comparison of the $\mathrm{CO}_{2}$-rebreathing method and electrical impedance cardiography. Physiol Meas 1997; 18: 327-338.

9. Quanjer PH, Tammeling GJ, Cotes JE, Pedersen OF, Peslin R, Yernault JC. Lung volumes and forced ventilatory flows. Report working party standardization of lung function tests, European Community for Steel and Coal. Official Statement of the European Respiratory Society. Eur Respir J 1993; 6: Suppl. 16, 5-40.

10. Kubicek WG, Kottke FJ, Ramos MU, Patterson TP, Witsoe DA, Mattson RH. Development and evaluation of an impedance cardiac output system. Aerosp Med 1966; 37 : $1208-1212$.

11. Woltjer HH, Arntzen BWGJ, Bogaard HJ, de Vries PMJM. Optimalization of spot electrodes array in impedance cardiography. Med Biol Eng Comput 1995; 34: 1-4.

12. Geddes LA, Sadler C. The specific resistance of blood at body temperature. Med Biol Eng 1973; 11: 336-339.

13. Fuller HD. The validity of cardiac output measurement by thoracic impedance: a meta analysis. Clin Invest Med 1992; 15: 103-112.

14. Miles DS, Gotshall RW. Impedance cardiography: noninvasive assessment of human central hemodynamics at rest and during exercise. In: Pandolf KB, ed. Exercise and Sport Sciences Reviews. Baltimore, Williams and Wilkins, 1989; pp. 231-263.

15. Hetherington MD, Teo KK, Haennel RG, Greenwood PV, Rosall RE, Kappagoda T. Use of impedance cardiography in evaluating the exercise response of patients with left ventricular dysfunction. Eur Heart J 1985; 6: 1016-1024.

16. Teo KK, Hetherington MD, Haennel RG, Greenwood PV, Rosall RE, Kappagoda T. Cardiac output measured by impedance cardiography during maximal exercise tests. Cardiovasc Res 1985; 19: 737-743.

17. Denniston JC, Maher J, Reeves J, Cruz J, Cymerman A, Grover R. Measurement of cardiac output by electrical impedance at rest and during exercise. J Appl Physiol 1976; 40: 91-95.

18. Milsom I, Silvertsson R, Biber B, Olsson T. Measurement of stroke volume with impedance cardiography. Clin Physiol 1982; 2: 409-417.

19. Du Quesnay MC, Stoute GJ, Hughson RL. Cardiac output in exercise by impedance cardiography during breath holding and normal breathing. J Appl Physiol 1987; 62: 101-107.

20. Niizeki K, Miyamoto Y, Doi K. A comparison between cardiac output determined by impedance cardiography and the rebreathing method during exercise in man. Jpn J Physiol 1989; 39: 441-446.

21. Muzi M, Ebert TJ, Tristani FE, Jeutter DC, Barney JA, Smith JJ. Determination of cardiac output using ensemble-averaged impedance cardiograms. J Appl Physiol 1985; 58: 200-205.

22. Zhang Y, Qu M, Webster JG, Tompkins WJ, Ward BA, Bassett DR. Cardiac output monitoring by impedance cardiography during treadmill exercise. IEEE Trans Biomed Eng 1986; 33: 1037-1041.

23. Qu M, Zhang Y, Webster JG, Tompkins WJ. Motion artefact from spot and band electrodes during impedance cardiography. IEEE Trans Biomed Eng 1986; 33: 1029-1036.

24. Bogaard HJ, Woltjer HH, Dekker BM, van Keimpema ARJ, Postmus PE, de Vries PMJM. The haemodynamic response to exercise in healthy young and elderly subjects. Eur J Appl Physiol 1997; 75: 435-442.

25. Ogawa T, Spina RJ, Martin WH, et al. Effects of aging, sex, and physical training on cardiovascular responses to exercise. Circulation 1992; 86: 494-503. 
26. Higginbotham MB, Morris KG, Sanders Williams R, McHale PA, Coleman RE, Cobb FR. Regulation of stroke volume during submaximal and maximal upright exercise in normal man. Circ Res 1986; 58: 281-291.

27. Åstrand PO, Rodahl K. Textbook of Work Physiology. Physiological Bases of Exercise. New York, McGrawHill, 1986; chapter 4.

28. Concu A, Marcello C. Stroke volume response to progressive exercise in athletes engaged in different types of training. Eur J Appl Physiol 1993; 66: 11-17.

29. Keul J, Dickhuth HH, Lehmann M, Steiger J. The athlete's heart, hemodynamics and structure. Int J Sports Med 1982; 3: 33-43.

30. Fleg JL, O'Connor F, Gerstenblith G, et al. Impact of age on the cardiovascular response to dynamic upright exercise in healthy men and women. $J$ Appl Physiol 1995; 78 : 890-900.

31. Matthay RA, Niederman MS, Wiedemann HP. Cardiovascular-pulmonary interaction in chronic obstructive pulmonary disease with special reference to the pathogenesis and management of cor pulmonale. Med Clin North Am 1990; 74: 571-618.

32. Macnee W. Pathophysiology of cor pulmonale in chronic obstructive pulmonary disease. Part I. Am J Respir Crit Care Med 1994; 150: 833-852.

33. Macnee W. Pathophysiology of cor pulmonale in chronic obstructive pulmonary disease. Part II. Am J Respir Crit Care Med 1994; 150: 1158-1168.

34. Mahler DA, Brent BN, Loke J, Zaret BL, Matthay RA. Right ventricular performance and central circulatory hemodynamics during upright exercise in patients with chronic obstructive pulmonary disease. Am Rev Respir Dis 1984; 130: 722-729.

35. Harris P, Segel N, Green I, Housley E. The influence of the airways resistance and alveolar pressure on the pulmonary vascular resistance in chronic bronchitis. Cardiovasc Res 1968; 2: 84-92.

36. Taylor R, Covell J, Sonnenblick E, Ross J. Dependence of ventricular distensibility on the filling of the opposite ventricle. Am J Physiol 1974; 213: 711-718.

37. Buda AJ, Pinsky MR, Ingels NB, Daughters GT, Stinson $\mathrm{EB}$, Alderman EL. Effect of intrathoracic pressure on left ventricular performance. N Engl J Med 1979; 301: 453-459.

38. Varray A, Mercier J, Savy-Pacaux AM, Préfaut C. Cardiac role in exercise limitation in asthmatic subjects with special reference to disease severity. Eur Respir J 1993; 6: 1011-1017.

39. Garfinkel SK, Kesten S, Chapman KR, Rebuck AS. Physiologic and nonphysiologic determinants of aerobic fitness in mild to moderate asthma. Am Rev Respir Dis 1992; 145: 741-745.

40. Carter R, Nicotra B, Huber G. Differing effects of airway obstruction on physical work capacity and ventilation in men and women with COPD. Chest 1994; 106: 1730-1739.

41. Render ML, Weinstein AS, Blaustein AS. Left ventricular dysfunction in deteriorating patients with chronic obstructive pulmonary disease. Chest 1995; 107: 162-168.

42. Burrows B, Earle RH. Course and prognosis of chronic obstructive lung disease. N Engl J Med 1969; 280: 397-404.

43. Morrison DA. Pulmonary hypertension in chronic obstructive pulmonary disease: the right ventricular hypothesis. Chest 1987; 92: 387-388. 